\title{
Influencing Factors on Tourists' Purchase Intention for Intangible Cultural Heritage Souvenir: A Case of Wangkui Shadow Souvenir
}

\author{
Haiying Liu',2, Chanchai Bunchapatanasakda ${ }^{3,4}$, Chuantong Zhang ${ }^{1}$, Shujuan Zhao², Dan Wang2 \\ ${ }^{1}$ School of Management, Shinawatra University, Bangkok, Thailand \\ ${ }^{2}$ Suihua University, Suihua, China \\ ${ }^{3}$ Shinawatra University, Bangkok, Thailand \\ ${ }^{4}$ DBA International Business Argosy University, Florida, USA \\ Email:332671963@qq.com, alaskatornado@gmail.com, liuxuyang3213@163.com
}

How to cite this paper: Liu, H.Y., Bunchapatanasakda, C.C., Zhang, C.T., Zhao, S.J. and Wang, D. (2019) Influencing Factors on Tourists' Purchase Intention for Intangible Cultural Heritage Souvenir: A Case of Wangkui Shadow Souvenir. Modern Economy, 10, 2264-2282.

https://doi.org/10.4236/me.2019.1011142

Received: October 12, 2019

Accepted: November 18, 2019

Published: November 21, 2019

Copyright $\odot 2019$ by author(s) and Scientific Research Publishing Inc. This work is licensed under the Creative Commons Attribution International License (CC BY 4.0).

http://creativecommons.org/licenses/by/4.0/

\begin{abstract}
Souvenir purchase has been considered as an important component of tourism, so it is necessary to understand the purchase intention and its antecedents. The research examined the influence of hedonic value, perceived problem, utilitarian value, customer satisfaction, attitude of protection and development on purchase intention. This research conducted an empirical study on one of intangible cultural heritage souvenirs, Wangkui shadow souvenirs. Selection of the sample was done by using purposive sampling with one criterion: the tourists who had travelled in Wangkui city. Data were collected by using questionnaires and 500 tourists participated in this study. The data were analyzed by using Structural Equation Modeling (SEM) with Amos computer program. The findings showed that hedonic value, utilitarian value had significant positive effect on customer satisfaction; customer satisfaction had a significant positive effect on purchase intention; hedonic value, utilitarian value had significant positive effect on attitude of protection and development; attitude of protection and development had a significant positive effect on the purchase intention; perceived problem had no significant positive effect on customer satisfaction and attitude of protection and development, but it had a significant negative effect on purchase intention.
\end{abstract}

\section{Keywords}

Intangible Cultural Heritages, Wangkui Shadow Souvenir, Hedonic Value, Utilitarian Value, Attitude of Protection and Development, Perceived Problem, Customer Satisfaction, Purchase Intention 


\section{Introduction}

\subsection{Background of the Study}

Shopping revenues is a symbol to identify tourism is developed or not. In the countries with developed tourism, tourism shopping accounts for $40 \%$ to $60 \%$ of tourism revenue. For example, souvenirs account for $50 \%$ of total tourism revenue in Swiss, while souvenirs account for 50\% - 55\% in Singapore and Hong Kong. For many tourists, the significant component of the shopping expenditure is purchasing souvenir [1]. It is necessary to understand purchase intention which is vital to develop and design souvenirs. Perceived value plays an important role in predicting behavioral intention. Among the customer value, hedonic and utilitarian values influence behavioral intention. Wilkins (2010) suggested similarly to Gordon (1986) that souvenir was used to approve that someone had achieved a particular experience. However, tourist experience was a complex construct [2]. Intangible Cultural Heritage can accommodate the needs of tourists to learn and experience the culture. However, before the tourists buy the souvenirs, they lack sensory experience of regional culture, rarely see the production process of souvenirs, and rarely participate in making souvenirs. In China, few souvenirs can be used usually. Most souvenirs are abandoned after the tourists return to daily life, and are difficult to be used by tourists.

\subsection{Problem State}

Intangible Cultural Heritage is the grand wisdom of the human being, and now it is the spirit of the dance on the precipice. In order to get rid of the survival crisis, it is not enough to rely on the country's financial protection and museum display, and it is vital to improve self-protection ability and the hematopoietic function. The selling of souvenirs can bring certain economic benefits, which can open up more living space for Intangible Cultural Heritage. Therefore, it is of great significance to explore the influencing factors on the tourists' purchase intention for Intangible Cultural Heritage souvenirs.

There are the following three reasons to take Wangkui shadow as an example in this study. First, Wangkui shadow is a diverse and comprehensive Intangible Cultural Heritage. The shadow is a distinct synthesis, including painting, sculpture, paper-cutting, opera and performance. Second, the public awareness of Wangkui shadow has been greatly improved. The local government has taken various measures to protect it, and has built up a special performance theater for it. In 2011, Chinese shadow was listed on the Human Intangible Cultural Heritage List. In 2015, Wangkui shadow combined with Yimakan, another world-class Intangible Cultural Heritage to interpret the Xiwenmorigen, made China golden lion award. More and more people began to understand the shadow. Third, Wangkui shadow has diversified derivatives. Wangkui shadow with a very high ornamental has spawned a live performance, experience. Wangkui shadow souvenirs with collection value, ornamental value and use value are produced. 
Tourists are the core and main body of tourism activities. From the perspective of tourists, to study the presented problems about purchase intention for the cultural heritage tourism can establish feedback. In this paper, the author analyzed the variables about tourists' psychological perception and attitude, then built a structural equation model and analyzing the influencing factors on the tourists' purchase intention, eventually gave some advice to develop souvenirs to satisfy the tourists' needs and perceptions.

\section{Literature Review}

\subsection{Research in Customer Perceived Value and Customer Satisfaction}

\subsubsection{Customer Perceived Value, Hedonic Value and Utilitarian Value}

The concept of value has proved to be an enduring endeavor for many philosophers and researchers [3]. A literature review has established that perceived value has been conceptualized as what consumers get for what they give, or the consumer's overall evaluation of the utility of a produce based on perceptions of what one receives for what one gives [4]. Perceived value has been considered one of the most important concepts for understanding customers. Perceived value is dimensional. Sheth et al. (1991) put forward perceived value includes social value, emotional value, functional value, epistemic value, and conditional value [5]. Utilitarian value and hedonic value are also included in perceived value. Utilitarian value refers to the level at which shopping is considered the "work" of obtaining a product because it is related to a certain sense of obligation felt in the process. Hedonic value is more subjective and personal than its utilitarian counterpart and resulting more from fun and playfulness.

\subsubsection{Customer Satisfaction}

Customer satisfaction is a core concept in marketing theory and practice. Customer satisfaction is an attitude towards the production or service. Customer satisfaction is a customer's overall evaluation of the performance of an offering to date [6]. Oliver (1996) stated that the customer satisfaction was the customer's fulfillment response. The next year, he described customer satisfaction as "a judgment that a product feature, or the product itself, provides pleasurable consumption related fulfillment". Customer satisfaction is assumed to be a determinant of repeat sales, positive word-of-mouth, and customer loyalty [7].

\subsection{Purchase Intention}

Fishbein and Ajzen (1980) believed that purchase intention was the subjective probability of consumers engaged in specific purchase behaviors. Dodds et al. (1991) believed that purchase intention was the possibility of consumers trying to purchase a certain product or brand [8]. From the perspective of the relationship between consumers' intention and purchase behavior, believed that to predict consumer behavior, first of all, it was necessary to understand the consumer wishes [9]. 


\subsection{Conceptual Framework}

In this study, the relationships among hedonic value, perceived problem, utilitarian value, customer satisfaction, attitude of protection and development, and purchase intention for Wangkui shadow souvenir are investigated.

Numerous researchers had verified the significant relationship between value and customer satisfaction [10]. The value included hedonic value, utilitarian value, emotional value, social value and so on. Some researchers found that customer perceived value was a positive and direct antecedent of customer satisfaction [11]. Hedonic and utilitarian values had a direct and significant influence on customer satisfaction [7]. Thus the first and fifth hypotheses (H1, H5) state that Hedonic value and utilitarian value of Wangkui shadow souvenirs have a significant and positive impact on customer satisfaction. Zhang Xiyue put forward the perceived attraction of intangible cultural heritage had a significant effect on attitude of protection, and attitude of protection had an effect on attitude of development [12]. Thus the second hypothesis (H2) states that hedonic value of Wangkui shadow souvenirs has a significant positive impact on attitude towards protection and development of Wangkui shadow souvenirs. When customer perceived high levels of value from consumption experience, they would be satisfied with the product, and they tended to have a positive intention. Many researchers had provided empirical evidence for a positive relationship between customer satisfaction and behavioral intention [13]. So the eighth hypothesis (H8) states customer satisfaction with Wangkui shadow souvenir has a significant positive impact on purchase intention. The perceived problem had a positive effect on attitude of protecting intangible cultural heritage, attitude of protecting intangible cultural heritage had a positive effect on attitude of development, and attitude of development had a positive effect on purchase intention. But the author put forward perceived problem had a negative effect on attitude of protection and development $(\mathrm{H} 4)$; perceived problem had a negative effect on purchase intention (H7); attitude of protection and development had a positive effect on purchase intention (H9). Based on the exploratory interview, the participants revealed that the more perceived problem, the less customer satisfaction; the stronger utilitarian value, the stronger attitude of protection and development. So the third hypothesis (H3) states Perceived problem of Wangkui shadow souvenir has a significant negative impact on customer satisfaction with Wangkui shadow souvenir. The sixth hypothesis (H6) states utilitarian value of Wangkui shadow souvenir has a significant positive impact on attitude towards protection and development of Wangkui shadow souvenir. In sum, the nine hypotheses are:

Hypothesis 1: Hedonic value of Wangkui shadow souvenir has a significant positive impact on customer satisfaction with Wangkui shadow souvenir.

Hypothesis 2: Hedonic value of Wangkui shadow souvenir has a significant positive impact on attitude towards protection and development of Wangkui shadow souvenir. 
Hypothesis 3: Perceived problem of Wangkui shadow souvenir has a significant negative impact on customer satisfaction with Wangkui shadow souvenir.

Hypothesis 4: Perceived problem of Wangkui shadow souvenir has a significant negative impact on attitude towards protection and development of Wangkui shadow souvenir.

Hypothesis 5: Utilitarian value of Wangkui shadow souvenir has a significant positive impact on customer satisfaction.

Hypothesis 6: Utilitarian value of Wangkui shadow souvenir has a significant positive impact on attitude towards protection and development of Wangkui shadow souvenir.

Hypothesis 7: Perceived problem of Wangkui shadow souvenir has a significant negative impact on purchase intention.

Hypothesis 8: Customer satisfaction with Wangkui shadow souvenir has a significant positive impact on purchase intention.

Hypothesis 9: Attitude towards protection and development of Wangkui shadow souvenir has a significant positive impact on purchase intention.

With a review of the relevant theory and literature, this paper exacts the influence factors on tourists' purchasing intention for intangible culture heritage souvenir, puts forward the hypothesis. Based on the above contents, especially on the Hypothesis model of tourists' perception and attitude towards traditional handicrafts of $\mathrm{ICH}$, the author constructed the hypothesis model of purchasing intention for intangible cultural heritage souvenirs (Figure 1).

\section{Methodology}

\subsection{Questionnaire Design and Collection of the Data}

\subsubsection{Questionnaire Design}

Questionnaire items were developed based on those used in previous researches. The questionnaire consisted of hedonic values and utilitarian values [14], the perceived problem and attitude towards protection and development [12], customer

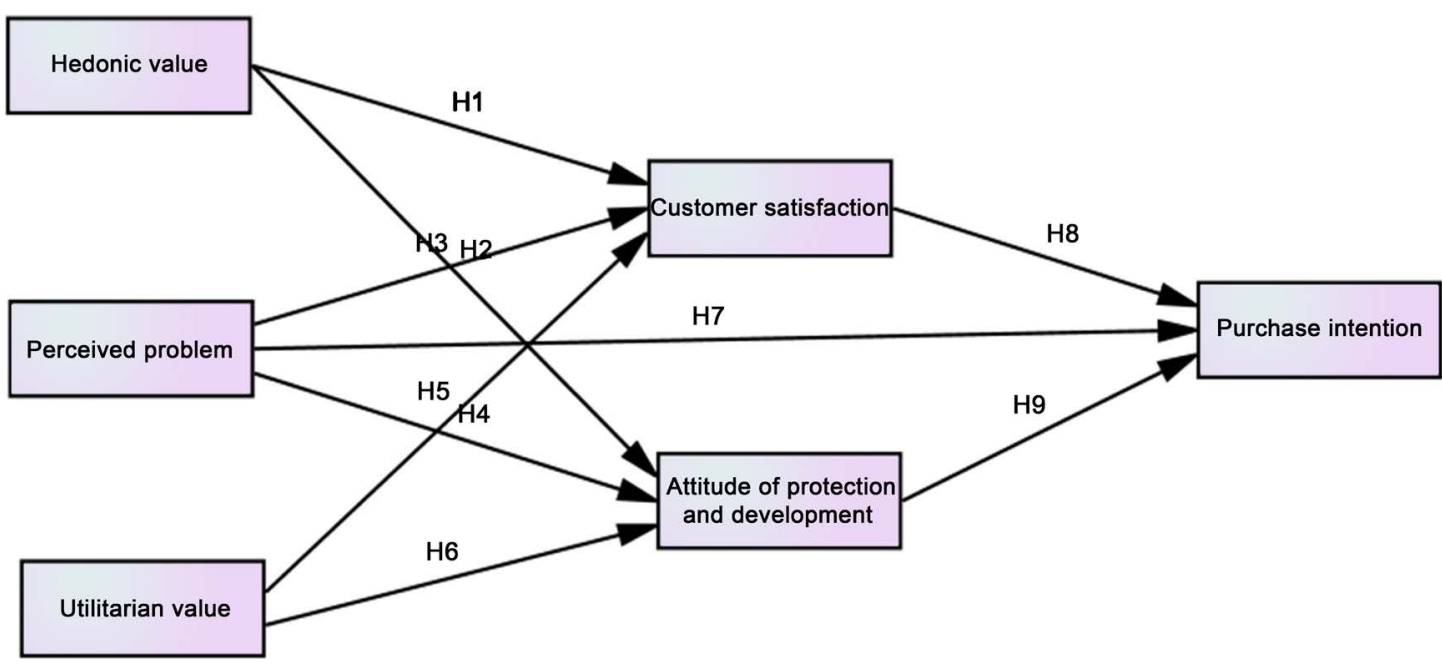

Figure 1. The proposed conception model. 
Table 1. Questions used in the study.

\begin{tabular}{|c|c|}
\hline & Questions \\
\hline \multirow[t]{3}{*}{ Hedonic value (HV) } & Wangkui shadow souvenir was fun and pleasant \\
\hline & Wangkui shadow souvenir had high ornamental value \\
\hline & Wangkui shadow souvenir was fantasy \\
\hline \multirow[t]{3}{*}{ Perceived problem (PP) } & The quality of the Wangkui shadow souvenir was not distinguishable \\
\hline & The exhibition of Wangkui shadow souvenir was not good enough \\
\hline & Wangkui shadow souvenir was not very well known \\
\hline \multirow[t]{4}{*}{ Utilitarian value (UV) } & Wangkui shadow souvenir can be used in study \\
\hline & Wangkui shadow souvenir can be used as the toys \\
\hline & Wangkui shadow souvenir can be used in daily days \\
\hline & The cost of Wangkui shadow souvenir is reasonable \\
\hline \multirow{3}{*}{$\begin{array}{l}\text { Customer satisfaction } \\
\text { (CS) }\end{array}$} & I was pleased to buy Wangkui shadow souvenir \\
\hline & The overall feeling I got form Wangkui shadow souvenir was satisfied \\
\hline & Trying a souvenir of Wangkui shadow was good \\
\hline \multirow{4}{*}{$\begin{array}{l}\text { Attitude of protection } \\
\text { and development (APD) }\end{array}$} & I would like to know more about the Wangkui shadow \\
\hline & I think the Wangkui shadow souvenirs is worthy of in-depth development \\
\hline & I would like to pay a fee to participate in the Wangkui shadow activity \\
\hline & I support the protection of the Wangkui shadow \\
\hline \multirow[t]{4}{*}{ Purchase intention (PI) } & I would like to pay a fee to participate in the Wangkui shadow activity \\
\hline & I would like to buy Wangkui shadow souvenir with ornamental value \\
\hline & I would like to buy more practical souvenir of Wangkui shadow \\
\hline & I would like to buy Wangkui shadow souvenirs online \\
\hline
\end{tabular}

Satisfaction [15], and purchase intention [8]. Respondents were asked to rate 20 items using a five-point Likert scale (Table 1).

\subsubsection{Collection Methods}

Data is the most valuable information that collected by the researchers from the respondents. Data can be readily quantified and generated into numerical form. It is ideal for use when surveying large numbers of respondents. The standardized nature of questionnaires enables researchers to make generalizations out of the results. In this research, the researcher used the quantitative method and the primary data by sending paper questionnaires to a large group of people which is more truthful with response.

\subsubsection{Population Sample}

In the research, the researcher distributed the questionnaires to the tourists who travelled in Wangkui. Research site is Wangkui city in Heilongjiang province, where the questionnaire were given to the tourists at cultural center, the Manchu garden, Lin feng's former residence, Miaoxiang mountain, Wangkui botanical gardens.

The respondents of my research are the tourists from different cities in china. 
The actual population of this study is the 500 tourists in Wangkui, Heilongjiang Province of China. These respondents mainly come from other cities in Heilongjiang Province which consist of teachers, students, staffs, businessmen and so on. Furthermore, the questionnaires are also distributed according to their different gender, age so as we can collect different types of information that provided by respondents based on their knowledge and experiences respectively. The actual population of this study is the 500 tourists in Wangkui, Heilongiiang Province of China.

\subsection{Methods of Data Analysis}

Data analysis technique used in this study is Structural Equation Model (SEM). SEM is a method based on strong theory so that SEM method is used to test a theory, both new theory developed by the researcher herself and old theory, in which empirical test is required to prove it. SEM is not only used to form the theory of causality but to test the existing theory of causality.

\subsection{Model Test}

In this study, 20 measurement items were involved, and the researcher distributed the questionnaire according to the ratio of 1:25, i.e. 500 questionnaires. The formal questionnaire began on December 1, 2018, and the collection of all data ended on January 15, 2019, lasting nearly one and a half months. The sample area is designed to be the main tourist attraction. A total of 500 questionnaires were distributed, and we received 426 responses, and the recovery rate was 85.2 percent, and the useful response was 401 , the response rate was 80.2 percent. The questionnaire mainly used Amos 21.0 and SPSS 21.0 for processing and analysis

\subsubsection{Reliability Test}

After the statistical validity of sample data, trend and distribution pattern basically meets the needs, this empirical research still needs to use the formal questionnaire reliability and validity test. Using the formal sample data collected by questionnaire survey, this study uses SPSS 21.0 software for the study of the six latent variables which is got by dimension reduction including 20 measuring items. Cronbach's alpha coefficient and alpha coefficients after deleting item were calculated respectively, and the specific results were shown in Table 2.

Data of table shows that the Cronbach's alpha coefficient of perceived attraction variable is 0.855 , Cronbach's alpha coefficient of perceived experience variable is 0.833 , Cronbach's alpha coefficient of perceived problem variable is 0.851 , Cronbach's alpha coefficient of practical demand variable is 0.873 , Cronbach's alpha coefficient of the attitude of the development of variable is 0.898 , Cronbach's alpha coefficient of purchase intention variable is 0.882 , and the variable scale delete any item after alpha coefficients were not significantly improved. Data at the same time, Cronbach's alpha coefficients of tourists' attitude and perception model is above 0.7 , reaching the standard of the reliability test [16], 
so the questionnaire used in this research has good reliability.

The combination reliability and convergent validity of the measurement model are further tested. The results as shown in Table 3, the combination reliability (CR) between 0.644 to 0.893 , is greater than 0.6 , which shows that the validity between latent variables and the observation variables is variables, model can be tested. The convergent validity of the measured model was tested with the average variation of the latent variable (AVE) to test the explanatory power of each observation variable on the average difference of the latent variable.

\subsubsection{Content Validity Test}

The validity analysis results of the study are as shown in the table, because the KMO value of each analysis indicator of the scale is greater than 0.7 , and is

Table 2. Reliability test.

\begin{tabular}{|c|c|c|c|}
\hline Variables & Code & Cronbach's $\alpha$ & Cronbach's $\alpha$ after deleting item \\
\hline \multirow{3}{*}{$\begin{array}{l}\text { Hedonic value } \\
\text { (HV) }\end{array}$} & HV1 & \multirow{3}{*}{0.855} & 0.787 \\
\hline & HV2 & & 0.813 \\
\hline & HV3 & & 0.790 \\
\hline \multirow{3}{*}{$\begin{array}{l}\text { Customer satisfaction } \\
\text { (CS) }\end{array}$} & CS1 & \multirow{3}{*}{0.833} & 0.784 \\
\hline & CS2 & & 0.748 \\
\hline & CS3 & & 0.776 \\
\hline \multirow{3}{*}{$\begin{array}{l}\text { Perceived problem } \\
\text { (PP) }\end{array}$} & PP1 & \multirow{3}{*}{0.851} & 0.788 \\
\hline & PP2 & & 0.740 \\
\hline & PP3 & & 0.776 \\
\hline \multirow{4}{*}{$\begin{array}{l}\text { Utilitarian value } \\
\text { (UV) }\end{array}$} & UV1 & \multirow{4}{*}{0.873} & 0.861 \\
\hline & UV2 & & 0.828 \\
\hline & UV3 & & 0.806 \\
\hline & UV4 & & 0.853 \\
\hline \multirow{3}{*}{$\begin{array}{l}\text { Attitude of protection } \\
\text { and development } \\
\text { (APD) }\end{array}$} & APD1 & \multirow{3}{*}{0.898} & 0.866 \\
\hline & APD2 & & 0.845 \\
\hline & APD3 & & 0.851 \\
\hline \multirow{4}{*}{$\begin{array}{l}\text { Purchase intention } \\
\text { (PI) }\end{array}$} & PI1 & \multirow{4}{*}{0.882} & 0.865 \\
\hline & PI2 & & 0.834 \\
\hline & PI3 & & 0.837 \\
\hline & PI4 & & 0.858 \\
\hline
\end{tabular}

Table 3. Default model reliability test.

\begin{tabular}{ccccccc}
\hline $\begin{array}{c}\text { Basic } \\
\text { dimensions }\end{array}$ & $\begin{array}{c}\text { Hedonic } \\
\text { value }\end{array}$ & $\begin{array}{c}\text { Customer } \\
\text { satisfaction }\end{array}$ & $\begin{array}{c}\text { Problem } \\
\text { perception }\end{array}$ & $\begin{array}{c}\text { Utilitarian } \\
\text { value }\end{array}$ & $\begin{array}{c}\text { Attitude of protection } \\
\text { and development }\end{array}$ & $\begin{array}{c}\text { Purchase } \\
\text { intention }\end{array}$ \\
\hline CR & 0.872 & 0.644 & 0.893 & 0.636 & 0.840 & 0.845 \\
AVE & 0.631 & 0.560 & 0.552 & 0.713 & 0.882 & 0.644 \\
\hline
\end{tabular}


significantly correlated with the level of 0.000 (Table 4). Therefore, the scale of this study has high validity.

\subsubsection{Initial Model Test}

In this study, AMOS 21.0 software was used to validate the data obtained from the formal investigation. Confirmatory factor analysis shows that the standardized load of all observed variables is from 0.72 to 0.89 (Figure 2), which conforms to the standard of being greater than 0.4 . The fitting result of the verification model is shown in Table 5. The data can be used to carry out the follow-up of path analysis in Table 6.

Structural equation model, according to the results of path coefficient analysis, six hypotheses among nine are significant at the 0.001 level, one significant is at the 0.01 level, the other two paths coefficient for example perceived problem and attitude of development, the problem of perception and perceived experience, according to $\mathrm{P}>0.05$, failed the test, so the effect was not significant. The

Table 4. Validity analysis of variables.

\begin{tabular}{ccccc}
\hline \multirow{2}{*}{ Scale category } & KMO test & \multicolumn{3}{c}{ Bartlett's test } \\
\cline { 3 - 5 } & & Chi-square test & Degree of freedom & Sig. \\
\hline Totle & 0.893 & 4927.173 & 190 & 0.000 \\
HV & 0.733 & 535.797 & 3 & 0.000 \\
UV & 0.815 & 826.111 & 6 & 0.000 \\
PP & 0.712 & 542.465 & 3 & 0.000 \\
CS & 0.724 & 464.391 & 3 & 0.000 \\
APD & 0.751 & 728.928 & 3 & 0.000 \\
PI & 0.838 & 878.149 & 6 & 0.000 \\
\hline
\end{tabular}

Note: $\mathrm{HV}=$ Hedonic value, $\mathrm{CS}=$ Customer satisfaction, $\mathrm{PP}=$ Perceived problem, UV = Utilitarian value, $\mathrm{APD}=$ Attitude of protection and development, $\mathrm{PI}=$ Purchase intention

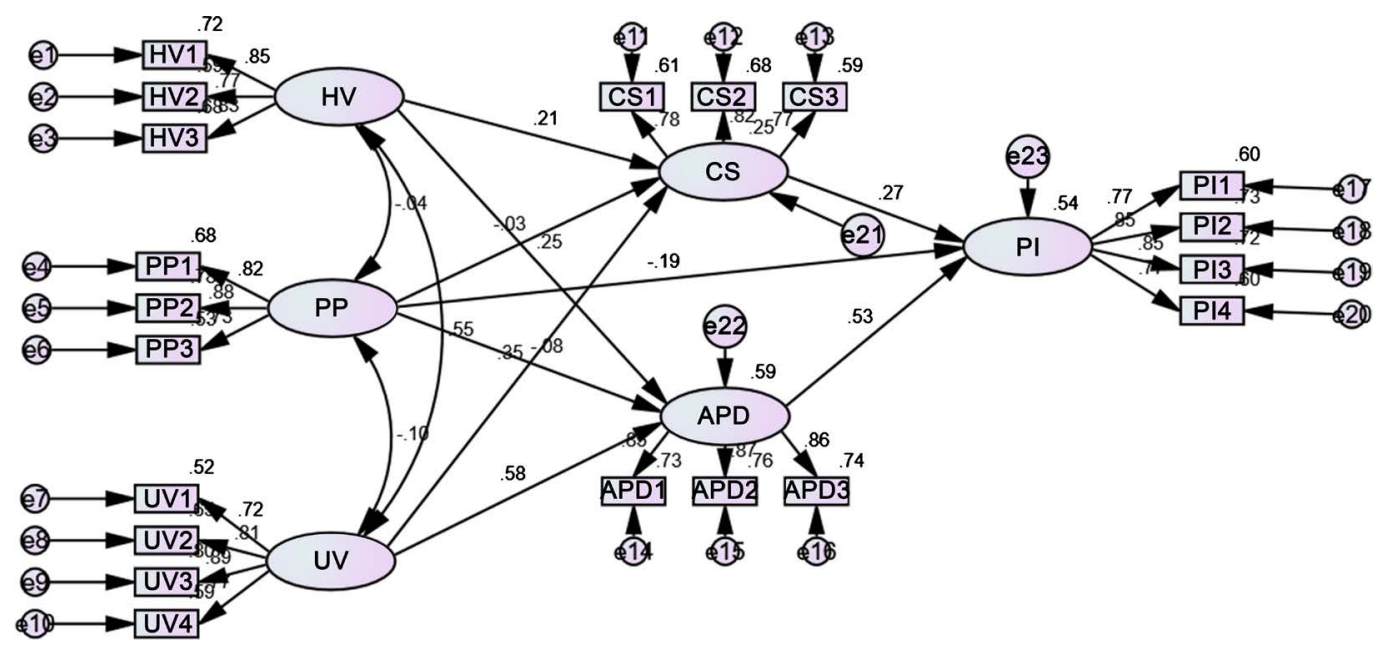

Note: $\mathrm{HV}=$ Hedonic value, $\mathrm{CS}=$ Customer satisfaction, $\mathrm{PP}=$ Perceived problem, UV $=$ Utilitarian value, APD $=$ Attitude of protection and development, PI = Purchase intention.

Figure 2. Parameter estimation of the model. 
Table 5. Fitting results of initial model.

\begin{tabular}{ccc}
\hline Indice & Value of the tested model & Desired value \\
\hline$\lambda^{2} / \mathrm{df}$ & 2.309 & Below 3 \\
GFI & 0.916 & Above 0.90 \\
NFI & 0.927 & Above 0.90 \\
CFI & 0.957 & Above 0.90 \\
RMSEA & 0.057 & Below 0.08 \\
SRMR & 0.0464 & Below 0.08 \\
\hline
\end{tabular}

Table 6. Hypothesis test results.

\begin{tabular}{lccccc}
\hline Hypothesis & Standardized regression weights & S.E. & C.R. & P & Status \\
\hline H1 CS $<$ HV & 0.144 & 0.046 & 3.144 & 0.002 & Supported \\
H2 APD $<$ HV & 0.205 & 0.043 & 4.790 & $* * *$ & Supported \\
H3 CS $<$ PP & -0.022 & 0.039 & -0.559 & 0.576 & Non-supported \\
H4 APD $<$ PP & -0.069 & 0.036 & -1.923 & 0.055 & Non-supported \\
H5 CS $<$ UV & 0.295 & 0.059 & 4.987 & $* * *$ & Supported \\
H6 APD $\leftarrow$ UV & 0.591 & 0.063 & 9.438 & $* * *$ & Supported \\
H7 PI $<$ PP & 0.410 & 0.079 & 5.205 & $* * *$ & Supported \\
H8 PI $<$ CS & 0.662 & 0.070 & 9.473 & $* * *$ & Supported \\
H9 PI $<$ APD & -0.213 & 0.049 & -4.346 & $* * *$ & Supported \\
\hline
\end{tabular}

Note: $\mathrm{HV}=$ Hedonic value, $\mathrm{CS}=$ Customer satisfaction, $\mathrm{PP}=$ Perceived problem, $\mathrm{UV}=$ Utilitarian value, $\mathrm{APD}=$ Attitude of protection and development, $\mathrm{PI}=$ Purchase intention.

performance factors were not analyzed further because it is in the area of not significant in the modified Kano model diagram.

\subsubsection{Revision and Inspection of the Model}

According to the test results, the researcher modified the initial model. In this study, the correction index (MI) of each parameter is small, considering the practical problems to be discussed in the model, the correction is not significant. Therefore, only the unmarked influence path of the variables in the model is deleted, and the modified structural equation model is shown in Figure 3.

In particular, for estimation of the fit of the model, the Maximum Likelihood with Bootstrapping of 1000 samples was adopted. The fitting test of the modified model is performed. The results are as follows in Table 7 . Table 7 shows that the fit of the model is good.

Structural Equation Model (SEM) analysis by using AMOS 21.0 was used to test the hypotheses proposed by the researcher. As the foundation to test the hypotheses, the Critical ratio (Cr) was used from the results of output regression weight. The hypotheses proposed will be accepted if $\mathrm{P}$ value $<$ the significance of $5 \%$. The results of the analysis are presented in Table 8.

As can be seen from the above table, 7 paths in the modified model, $\mathrm{H} 1, \mathrm{H} 2$, 


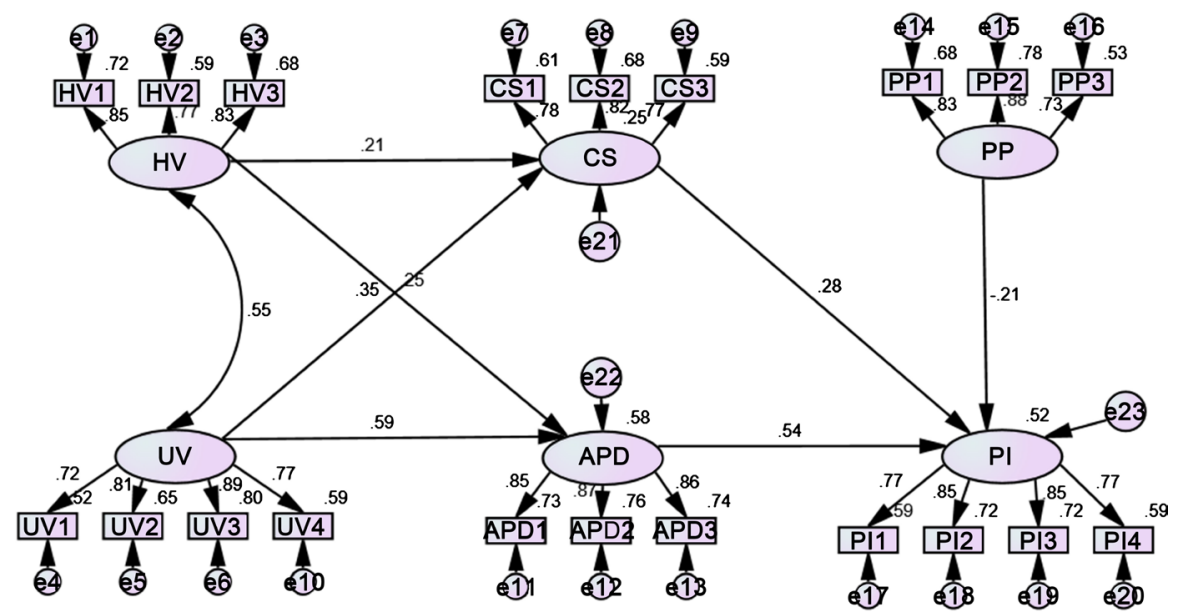

Note: $\mathrm{HV}=$ Hedonic value, $\mathrm{CS}=$ Customer satisfaction, $\mathrm{PP}=$ Perceived problem, UV $=$ Utilitarian value, $\mathrm{APD}=$ Attitude of protection and development, $\mathrm{PI}=$ Purchase intention

Figure 3. Modified structural equation mode.

Table 7. Fitting results of modified model.

\begin{tabular}{ccc}
\hline Indice & Value of the tested model & Desired value \\
\hline$\lambda^{2} / \mathrm{df}$ & 2.300 & Below 3 \\
GFI & 0.914 & Above 0.90 \\
NFI & 0.926 & Above 0.90 \\
CFI & 0.914 & Above 0.90 \\
RMSEA & 0.057 & Below 0.08 \\
SRMR & 0.0575 & Below 0.08 \\
\hline
\end{tabular}

Table 8. Analysis results of regression weight.

\begin{tabular}{lccccc}
\hline \multirow{2}{*}{ Hypothesis } & \multicolumn{5}{c}{ Standardized regression } \\
\cline { 2 - 6 } & Weights & S.E. & C.R. & P & Status \\
\hline H1 CS $<$ HV & 0.144 & 0.046 & 3.131 & 0.002 & Supported \\
H2 APD $<$ HV & 0.204 & 0.043 & 4.741 & $* * *$ & Supported \\
H5 CS $<$ UV & 0.298 & 0.059 & 5.057 & $* * *$ & Supported \\
H6 APD $<$ UV & 0.601 & 0.063 & 9.546 & $* * *$ & Supported \\
H7 PI $<$ PP & -0.226 & 0.048 & -4.677 & $* * *$ & Supported \\
H8 PI $<$ CS & 0.412 & 0.079 & 5.221 & $* * *$ & Supported \\
H9 PI $<$ APD & 0.664 & 0.070 & 9.541 & $* * *$ & Supported \\
\hline
\end{tabular}

Note: ${ }^{* *}$ significant in level of $0.001 ; \mathrm{HV}=$ Hedonic value, $\mathrm{CS}=$ Customer satisfaction, $\mathrm{PP}=$ Perceived problem, $\mathrm{UV}=$ Utilitarian value, $\mathrm{APD}=$ Attitude of protection and development, $\mathrm{PI}=$ Purchase intention

$\mathrm{H} 5, \mathrm{H} 6, \mathrm{H} 7, \mathrm{H} 8$ and $\mathrm{H} 9$ all pass the test and $\mathrm{P}<0.05$, which is consistent with the expected effect. Therefore, the final model path of this study is shown in Figure 4.

\section{Research Findings and Discussion}

\subsection{Sample Demographic Characteristics}

The details of the sample distribution are shown in Table 9. Of the responses, in 


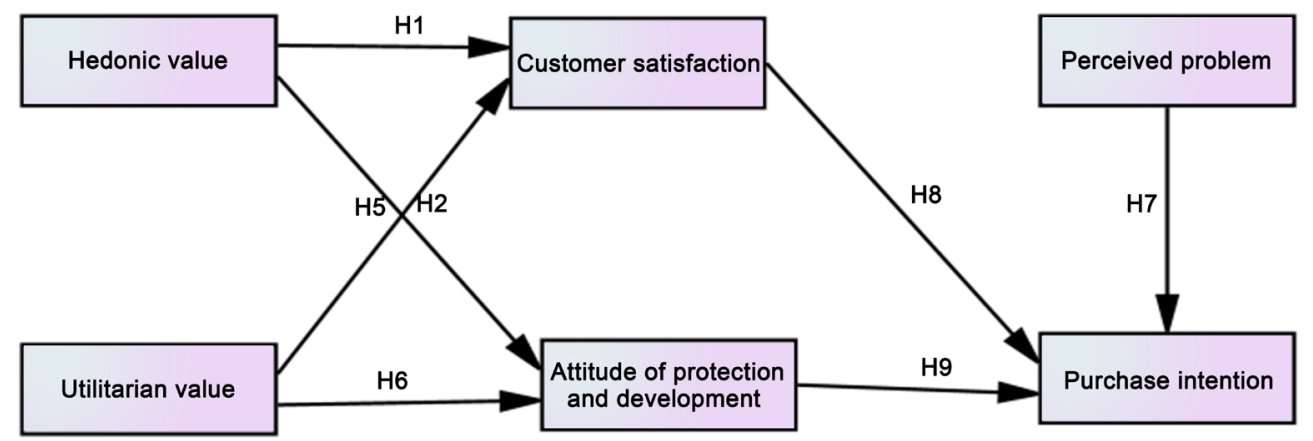

Figure 4. Model of the tourists' purchase intention for the intangible cultural heritage souvenir.

Table 9. Demographic and characteristics of respondents $(\mathrm{N}=401)$.

\begin{tabular}{|c|c|c|c|}
\hline Feature & Category & Num & Percent \\
\hline \multirow[t]{2}{*}{ Gender } & Man & 166 & $41.4 \%$ \\
\hline & Woman & 235 & $58.6 \%$ \\
\hline \multirow[t]{6}{*}{ Age } & Below 18 & 7 & $1.7 \%$ \\
\hline & $19-23$ & 107 & $26.7 \%$ \\
\hline & $24-35$ & 86 & $21.4 \%$ \\
\hline & $36-45$ & 165 & $41.1 \%$ \\
\hline & $46-60$ & 33 & $8.2 \%$ \\
\hline & Above 60 & 3 & $0.7 \%$ \\
\hline \multirow[t]{7}{*}{ Occupation } & Public & 175 & $43.6 \%$ \\
\hline & Institution & & \\
\hline & Self-employed & 59 & $14.7 \%$ \\
\hline & Company employee & 34 & $8.5 \%$ \\
\hline & Peasant & 10 & $2.5 \%$ \\
\hline & Student & 119 & $29.7 \%$ \\
\hline & Retired & 4 & $1 \%$ \\
\hline \multirow[t]{4}{*}{ Education } & Junior and below & 26 & $6.5 \%$ \\
\hline & High school & 48 & $12 \%$ \\
\hline & College & 309 & $77.1 \%$ \\
\hline & Graduate & 18 & $4.5 \%$ \\
\hline \multirow[t]{5}{*}{ Price selection } & Below $50 \mathrm{RMB}$ & 108 & $26.9 \%$ \\
\hline & 50 - 99 RMB & 167 & $41.6 \%$ \\
\hline & $100-199 \mathrm{RMB}$ & 75 & $18.7 \%$ \\
\hline & 200 - 299 RMB & 29 & $7.2 \%$ \\
\hline & Above300 RMB & 22 & $5.5 \%$ \\
\hline
\end{tabular}

terms of gender, the male and female gender ratio is 41.4 percent to 58.6 percent, which means the female tourists are nearly equal male tourists in this survey. The age category with the largest representation was 36 - 45 years with 41.1 percent, followed by 19 - 23 with 26.7 percent. Regarding education, 77 percent of the sample reported that the most degree attained of the respondents was ba- 
chelor degree or college degree. These groups fit well with the characteristics of the mainstream consumer groups in Chinese society and have a good representativeness. In general, the formal sampling survey has statistical validity. The detailed analysis is as follows.

\subsection{Analysis of the Influencing Factors on Tourists' Purchasing Intention of Intangible Cultural Heritage Souvenir}

\subsubsection{The Effect of Hedonic Value on Customer Satisfaction}

The test results of the influence of hedonic value on customer satisfaction generate value of the standard path coefficient by 0.21 (Figure 3), with value $\mathrm{Cr}$ amounted to 3.131 in the significance level of 0.002, less than 0.01 (Table 8). This study suggests that hedonic value has a positively significant effect on customer satisfaction.

The average ranking of tourist hedonic value is "fun" (4.12), fantasy (3.86) and ornamental value (3.77). It is worth noting that women's perception of heritage attractions average slightly higher than the men, women awareness to fantasy (3.76), the men's perception for the "fun"(4.13) and ornamental value (3.80) is slightly higher than the female's, and no significant difference between the man and the woman. In general, the ornamental value is in an important position, so the intangible cultural heritage with aesthetic value is of great value for tourism development. Statistics show that $87 \%$ of visitors who tried the souvenirs felt good, $78.6 \%$ of tourists were satisfied with Wangkui shadow souvenirs, $66.8 \%$ of visitors were pleased to buy Wangkui shadow play.

\subsubsection{The Effect of Hedonic Value on Attitude of Protection and Development}

The influence of hedonic value on attitude of protection and development generated the value of standard coefficient path amounted to 0.25 with $\mathrm{Cr}$ value of 4.741, $\mathrm{p}$ is less than 0.001 . Table 8 shows that hypothesis $\mathrm{H} 2$ is supported, namely the Intangible Cultural Heritage souvenir's hedonic value has a significant positive effect on attitude of protection and development. Those results explain that tourists will support the protection and development of souvenirs who felt the hedonic value of Intangible Cultural Heritage souvenir because they may think it is worth protecting and developing.

Wangkui shadow was fantasy (HV3, 0.89), Wangkui shadow souvenir was fun (HV1, 0.85), and Wangkui shadow had high ornamental value (HV2, 0.82) are the important perceptive factors of Intangible Cultural Heritage attraction. The survey found that $65.09 \%$ of the tourists had a "very good agreement" or "consent" attitude to "Wangkui shadow's high ornamental value". Wangkui shadow, as one of the Intangible Cultural Heritage, is an integrated folk art. Visitors can not only enjoy the northern folk opera unique rap and traditional instruments, but also can see a map of Wangkui shadow in art design. The characteristics of scatter plot perspective, gorgeous color, simplify and the hyperbole deeply rooted in the hearts of the tourists. 


\subsubsection{The Effect of Utilitarian Value on Customer Satisfied}

From Table 8, the hypothesis 5 discusses the relations between utilitarian value and customer satisfaction, assuming that the content of "there is a significant positive correlation between utilitarian value with customer satisfaction", and from Table 8 and Figure 3, we can see the standard path coefficient was 0.35 $(\mathrm{CR}=5.057), \mathrm{P}<0.001$, shows that hypothesis $\mathrm{H} 5$ is supported, the utilitarian value has significant positive influence on customer satisfaction, tourists' love for the goods availability can affect the customer satisfaction with intangible cultural heritage souvenirs. Among them, Wangkui shadow souvenir can be used in study (UV1, 0.79), Wangkui shadow souvenir can be toys (UV2, 0.82), Wangkui shadow souvenir can be used in daily day (UV3, 0.88), the cost is reasonable (UV4, 0.76), are the key effect factors of the experience of Intangible Cultural Heritage perception.

\subsubsection{The Effect of Utilitarian Value Attitude of Protection and Development}

From Table 8, Hypothesis 6, the relationship between the utilitarian value and attitude of protection and development, assumes "utilitarian value has a significant positive correlation with the protection and development of souvenir". The test results show that the $\mathrm{P}<0.001$, and the standard path coefficient was 0.59 $(\mathrm{CR}=9.546)$, that hypothesis $\mathrm{H} 6$ can be verified, the utilitarian value has a significant positive effect on attitude of souvenir's protection and development, so knowing what your preferences are and enhancing the usage function of souvenirs can enhance the support of tourists on the souvenir's protection development.

\subsubsection{The Effect of Perceived Problem on Purchase Intention}

Hypothesis 7 assumes that "perceived problem associates negatively with the purchase intention", seen from Table 9 and Figure 3, the path coefficient was $-0.210(\mathrm{CR}=-4.677), \mathrm{P}<0.001$, suggesting that Hypothesis 7 is verified. Recognizing the problems in the market, the tourists directly show their resistance to the purchase of Intangible Cultural Heritage souvenirs. Among them, the most powerful influence on the purchase intention is the display environment and mode (PP2, 0.83), profile (PP3, 0.60), and again, the quality judgment (PP1, $0.50)$.

The field research shows that window display can be seen usually on the souvenir market of the Intangible Cultural Heritage, which is not only presented in a single way, but also the environment and atmosphere of shopping are common. To fully demonstrate the profound culture of Intangible Cultural Heritage requires combination many means of presentation and commentary. In addition to the on-site presentation, the professional explanation and interaction with the heir of Intangible Cultural Heritage are the ways to get the greater recognition of tourists. In the souvenir market of the Intangible Cultural Heritage, when the production is statically displayed, the process of making should be provided, with professional cultural explanation, which can increase the chances to interact 
with the artists, can achieve "live show-professional explanation-interactionshopping" chain of souvenir development mode.

\subsubsection{The Effect of Customer Satisfaction on Purchase Intention}

Hypothesis 8 is to discuss the relationship between customer satisfaction and purchase intention, assumes "customer satisfaction has a positive and significant impact on the purchase intention". Test results show that the path coefficient was $0.28(\mathrm{CR}=5.221), \mathrm{P}<0.001$, so the relation is supported by SEM. In other words, the better the tourists' satisfaction with Wangkui shadow souvenirs, the stronger the purchase intention. So enhancing tourists' satisfaction can enhance the tourists' willingness to buy souvenirs. Be pleased to buy Wangkui shadow souvenir (CS1, 0.700), the feeling for Wangkui shadow souvenir is pleased (CS2, 0.650 ), and the trial experience of tourist souvenirs (CS3, 0.680) were important factors affecting the purchase intention.

After visitors feel the charm of intangible, they will form the purchase intention, be willing to buy souvenirs of ornamental value (PI2, 0.840), and be willing to pay to attend activities associated with Wangkui shadow (PI4, 0.840).

\subsubsection{The Effect of Attitude of Protection and Development on Purchase Intention}

Hypothesis 9 is to discuss the relation between attitude of protection and development and purchase intention, assumes "the attitude of development has a positive and significant impact on purchase intention". Test results show that the path coefficient was $0.54(\mathrm{CR}=9.541), \mathrm{P}<0.001$, so the relation is supported by SEM. In other words, the higher the tourists will support the protection and development of intangible cultural heritage, the stronger they will pay for Intangible Cultural Heritage tourism. The desire to know more knowledge of Wangkui shadow (APD1, 0.850), and Supporting the protection of Wangkui shadow (APD2, 0.890), supporting the development of Wangkui shadow (APD3, 0.850 ) are the main factors influencing the willingness to pay.

\section{Conclusion and Recommendation}

\subsection{Conclusion}

From Figure 4, we can see there are 7 hypotheses are supported: hedonic value of Wangkui shadow souvenir has a significant positive impact on customer satisfaction with Wangkui shadow souvenir, hedonic value of Wangkui shadow souvenir has a significant positive impact on attitude towards protection and development of Wangkui shadow souvenir, utilitarian value of Wangkui shadow souvenir has a significant positive impact on customer satisfaction, utilitarian value of Wangkui shadow souvenir has a significant positive impact on attitude towards protection and development of Wangkui shadow souvenir, perceived problem of Wangkui shadow souvenir has a significant negative impact on purchase intention, customer satisfaction with Wangkui shadow souvenir has a significant positive impact on purchase intention, attitude towards protection and 
development of Wangkui shadow souvenir has a significant positive impact on purchase intention.

\subsection{Recommendation}

\subsubsection{Tap the Value of Intangible Cultural Heritage}

Intangible cultural heritage is the crystallization of human wisdom with rich value, which can attract tourists' attention. Take shadow play for example, shadow is presented to the world with a clear artistic beauty, the spirit of craftsman, and the humanistic spirit of the heavy history. Chinese shadow first appeared in Han dynasty in that time the material was not rich, craftsmen's elaboration showed all the colors of the rainbow life, highlighted the life rich and colorful side which show they loved their lives. This is the first one of the humanistic spirits of shadow: love life. Shadow craftsmen used color not much, mainly five kinds of pure color, did not mix impurity doping, let person feel positive and clear. This is the second humanistic spirit of shadow puppets: simply living. Shadow puppetry is called "the oldest cartoon in the world" and adopts simplified, humorous and even cartoonish ways to depict the simple and unsophisticated style. This is the third human spirit of shadow puppetry: life with optimism. There are many auspicious patterns in shadow patterns, which express people's good wishes for life. This is the fourth human spirit of shadow: full of hope for life. In a word, one sentence can sum up the humanistic spirit of shadow: the praise of ordinary life and the yearning for a better life. These spirits should be displayed in the souvenirs of shadow.

\subsubsection{Pay Attention to the Usefulness}

One of the reasons for the gradual decline of Intangible Cultural Heritage is that it is divorced from the daily life of modern people, which leads to the atrophy of market. The usage of the traditional cultural goods declines in modern life, whose original function has not been needed by modern life. The trend of souvenirs is that the groceries with practical value and reasonably price are popular with tourists. Therefore, when developing the souvenirs it is necessary to pay attention to the useful elements to create souvenirs that tourists like, rather than simple replicas of scenic spots and local features. It requires cross-boundary thinking, making souvenirs into the life, and let it be the living things, with more application scenarios, and more sharing value.

Good souvenirs should also be used in real life. For example, designing and developing shadow souvenirs with practical function can deconstruct elements of the shadow, then put the elements into the practical material carrier, forming useful souvenirs such as shadow clocks, shadow tea set, the shadow background wall, the shadow handbag, shadow desk calendar, shadow stationery, shadow lamp and so on.

\subsubsection{Increase the Public Welfare Culture Propaganda and Professional Explanation}

Intangible Cultural Heritage market should take on the role of cultural transmis- 
sion, through the layout of Intangible Cultural Heritage museum, showroom, surrounding the history and culture, art techniques, make the culture display with public welfare to help the visitors get Intangible Cultural Heritage knowledge, which is an important aspect of the development of Intangible Cultural Heritage souvenirs. Now there are many problems at the Intangible Cultural Heritage souvenir market such as quality failure. To increase Intangible Cultural Heritage knowledge propaganda to the ordinary tourists, can improve the discrimination of visitors, attributing to standardize the market. Culture show and preach also can let visitors further recognize the protection and inheritance significance of Intangible Cultural Heritage, the Intangible Cultural Heritage productive protection ways, which support the Intangible Cultural Heritage souvenirs development. The tourists' buying souvenirs and bringing them to all over the world, can spread the Intangible Cultural Heritage culture, and expand the Intangible Cultural Heritage living space. Research shows that tourists have lower willingness to pay for cultural propaganda and professional explanation, so additional fees will be at a low degree of market response.

\subsection{Limitations and Suggestions for Future Research}

First, this study focused on Wangkui shadow souvenir segment, whereas the intangible cultural heritage has different segments. This geographical limitation may produce different results and conclusions in terms of the purchase intention of intangible cultural heritage souvenir. In the future, the researcher can study other intangible cultural heritage souvenirs such as silk, ceramic and so on.

Second, the use of tourists in Wangkui sample, while it may be limited the generalizability of the study findings.

Third, the study suggested the direct relationship of hedonic and utilitarian values on customer satisfaction and attitude of protection and development; direct influence of customer satisfaction and attitude of protection and development on purchase intention. Thus future research can examine the structural relations, including the influence of hedonic and utilitarian values on purchase intention.

In addition, future research can include the other perceived values such as emotional value, social value and so on.

\section{Funding}

This paper is from the Project Supported by the National Natural Science Foundation of China (Grant No. 71673015/G031031); Project of Philosophy and Social Science Research of Heilongjiang Province of China (Grant No. 17YSE395); Project of Art and Science of Heilongjiang Province of China (Grant No. 2016D109); Fundamental Research Funds of Department of Education Heilongjiang Province of China (Grant No. KYYWF10236180221); Key Project of Suihua University of Heilongjiang Province of China (Grant No. H201701002). 


\section{Conflicts of Interest}

The authors declare no conflicts of interest regarding the publication of this paper.

\section{References}

[1] Kim, S. and Littrell, M.A. (2001) Souvenir Purchase Intentions for Self versus Others. Annals of Tourism Research, 28, 638-657. https://doi.org/10.1016/S0160-7383(00)00064-5

[2] Neuhofer, B., Buhalis, D. and Ladkin, A. (2015) Technology as a Catalyst of Change: Enablers and Barriers of the Tourist Experience and Their Consequences. In: Tussyadiah, I. and Inversini, A., Eds., Information and Communication Technologies in Tourism 2015, Springer Verlag, Lugano, 789-802. https://doi.org/10.1007/978-3-319-14343-9 57

[3] Babin, B.J., Darden, W.R. and Griffin, M. (1994) Work and/or Fun: Measuring Hedonic and Utilitarian Shopping Value. The Journal of Consumer Research, 20, 644-656. https://doi.org/10.1086/209376

[4] Ryuk, Lee, H.R. and Gon, K.W. (2012) The Influence of the Quality of the Physical Environment, Food, and Service on Restaurant Image, Customer Perceived Value, Customer Satisfaction, and Behavioral Intention. International Journal of Contemporary Hospitality Management, 2, 200-223. https://doi.org/10.1108/09596111211206141

[5] Sheth, J.N., Newman, B.I. and Gross, B.L. (1991) Why We Buy What We Buy: A Theory of Consumption Values. Journal of Business Research, 2, 159-170. https://doi.org/10.1016/0148-2963(91)90050-8

[6] Johnson, M.D. and Fornell, C. (1991) A Framework for Comparing Customer Satisfaction across Individuals and Product Categories. Journal of Economic Psychology, 12, 267-286. https://doi.org/10.1016/0167-4870(91)90016-M

[7] Ryu, K. and Han, H. (2010) Influence of the Quality of Food, Service, and Physical Environment on Customer Satisfaction and Behavioral Intention in Quick-Casual Restaurants: Moderating Role of Perceived. Journal of Hospitality \& Tourism Research, 34, 310-329. https://doi.org/10.1177/1096348009350624

[8] Dodds, M. and Kent, B. (1991) Effects of Price, Brand, and Store Information on Buyers' Product Evaluations. Journal of Marketing Research, 28, 307-319. https://doi.org/10.1177/002224379102800305

[9] Kim, S. and Littrell, M.A. (1999) Predicting Souvenir Purchase Intentions. Journal of Travel Research, 2, 153-162. https://doi.org/10.1177/004728759903800208

[10] Taylor, J. (2001) Authenticity and Sincerity in Tourism. Annals of Tourism Research, 1, 7-26. https://doi.org/10.1016/S0160-7383(00)00004-9

[11] Chen, C.F. and Tsai, D.C. (2007) How Destination Image and Evaluative Factors Affect Behavioral Intentions? Tourism Management, 28, 1115-1122. https://doi.org/10.1016/j.tourman.2006.07.007

[12] Zhang, X.Y. and Chen, T. (2016) Influence Mechanism of Tourism Development on Intangible Cultural Heritages (ICH) Based on the Perception of Tourists: A Case Study of Traditional Handicraft Suzhou Embroidery. Geographical Research, 35, 590-604.

[13] Young, N. and Jang, S. (2007) Does Food Quality Really Matter in Restaurants? Its Impact on Customer Satisfaction and Behavioral Intentions. Journal of Hospitality \& Tourism Research, 3, 387-409. https://doi.org/10.1177/1096348007299924 
[14] Babina, B.J. and Attawayb, J.S. (2000) Atmospheric Affect as a Tool for Creating Value and Gaining Share of Customer. Journal of Business Research, 2, 91-99. https://doi.org/10.1016/S0148-2963(99)00011-9

[15] Yi, Y.J. and La, S.N. (2004) What Influences the Relationship between Customer Satisfaction and Repurchase Intention? Investigating the Effect of Adjusted Expectations and Customer Loyalty. Psychology and Marketing, 5, 351-373. https://doi.org/10.1002/mar.20009

[16] Nunnally, J.C. (1978) Psychometric Theory. 2nd Edition, McGraw-Hill, New York. 